DOI: http://dx.doi.org/10.23925/2176-2767.2020v68p113-141

Recebido 29/03/2020

Aprovado: 01/07/2020

\title{
AUTORITARISMO, AJUSTE ESTRUTURAL E NEOLIBERALISMO: RUANDA APÓS O GENOCÍDIO DE 1994
}

\section{AUTHORITARIANISM, STRUCTURAL ADJUSTMENT AND NEOLIBERALISM: RWANDA AFTER THE 1994 GENOCIDE}

\author{
DANILO FERREIRA DA FONSECA ${ }^{1}$
}

\begin{abstract}
RESUMO
O Presente artigo visa refletir sobre os caminhos seguidos por Ruanda no período pósgenocídio de 1994, principalmente no que tange o modo que o governo da Frente Patriótica Ruandesa, liderado pelo General Paul Kagame, administra a política interna e a política econômica do país. Com uma postura autoritária frente à oposição, reprimindo vozes dissidentes até mesmo dentro de seu próprio partido, Paul Kagame, administra o país com mão de ferro, ao passo que busca implementar políticas neoliberais no âmbito econômico, o que afeta diretamente o modelo de desenvolvimento do país e os trabalhadores ruandeses. Com prestígio frente a órgãos internacionais como o Banco Mundial e potências ocidentais, Ruanda tem sido colocada como um modelo de referência para o desenvolvimento do continente africano, daí a urgência de refletir sobre o caráter autoritário e neoliberal proposto pela Frente Patriótica Ruandesa e suas consequências para a população ruandesa. $\mathrm{O}$ presente artigo faz parte dos resultados obtidos no decorrer da pesquisa de pós-doutoramento na Universidade Federal do ABC (UFABC) no Programa de Pós-graduação em Economia Política Mundial.
\end{abstract}

PALAVRAS-CHAVE: Ruanda; Frente Patriótica Ruandesa; Autoritarismo; Ajuste estrutural.

${ }^{1}$ Pós-doutor pelo Programa de Pós-graduação em Economia Política Mundial (PPGEPM) da Universidade Federal do ABC (UFABC), Professor Adjunto da Universidade Estadual do Centro-Oeste do Paraná (UNICENTRO) lotado no Departamento de História de Irati (DEHIS/I), Professor Colaborador do Programa de Pós-graduação em História (PPGH) da Unicentro. E-mail: daniloffonseca@gmail.com Orcid: https://orcid.org/0000-0001-6887-612X 


\begin{abstract}
The present article aims to reflect on the paths followed by Rwanda in the post-genocide period of 1994, mainly with regard to the way in which the government of the Rwandan Patriotic Front, led by General Paul Kagame, manages the country's internal and economic policies. With an authoritarian stance towards the opposition, repressing dissenting voices even within his own party, Paul Kagame, manages the country with an iron fist, while seeking to implement neoliberal policies in the economic sphere, which directly affects the development model of the country. country and Rwandan workers. With prestige vis-à-vis international bodies such as the World Bank and Western powers, Rwanda has been placed as a reference model for the development of the African continent, hence the urgency to reflect on the authoritarian and neoliberal character proposed by the Rwandan Patriotic Front and its consequences for the Rwandan population. This article is part of the results obtained during the post-doctoral research at the Federal University of ABC (UFABC) in the Postgraduate Program in World Political Economy.
\end{abstract}

KEYWORDS: Rwanda; Rwandan Patriotic Front; Authoritarianism; structural adjustment.

\title{
Considerações iniciais
}

Com o término do genocídio de 1994, Ruanda passou por um longo período de dominação por parte da Frente Patriótica Ruandesa (FPR), tendo como principal figura política o atual presidente Paul Kagame, general e líder da organização armada oposicionista ao regime de Juvenal Habyarimana.

No decorrer do período de domínio da FPR, o país se caracterizou por um crescimento econômica acelerado (acima da média africana e mundial), que ocorre simultaneamente a uma série de reformas estruturais que envolvem o Estado ruandês, o mundo do trabalho e o acesso à terra, além da repetição de episódios autoritários.

A atuação do governo de Paul Kagame tem colocado Ruanda nos holofotes internacionais, rendendo uma série de elogios na mesma medida em que é criticado. Por um lado, o presidente Paul Kagame é visto como 
uma político visionário, que deveria servir de referência para o restante do continente africano, conforme é destacado por órgãos ocidentais como o Banco Mundial, ou ainda meios de comunicação, como foi o caso da Revista Forbes África que elegeu Kagame como a personalidade do ano de 2018. Por outro lado, organizações criticam a dureza e a repressão política promovidas pelo governo de Kagame, o que é constantemente denunciado por órgãos humanitários, como é o caso da Anistia Internacional que aponta principalmente a violação de direitos humanos, ou ainda a falta de liberdade política.

Essa ambiguidade de visões acerca da política ruandesa do pósgenocídio de 1994 também é expressa na literatura acadêmica especializada em que intelectuais de diferentes áreas expressam análises com caráter positivo ou crítico frente aos caminhos recentes seguidos na política ruandesa. Para intelectuais como Blair e Buffet (2013), Clark (2010), Gourevitch (2009) e Kinzer (2008), a Frente Patriótica Ruandesa conseguiu promover a reconciliação de um país dividido, tornando Ruanda um país estável, além de um modelo de desenvolvimento que promove um constante crescimento econômico para o país. Já para intelectuais como Ansoms (2011), Kayumba (2010), Straus e Waldorf (2011), Reyntjens (2004), as supostas conquistas do governo de Paul Kagame seriam a expressão de um governo autoritário, com um modelo político repressivo e que acaba por massacrar a vida dos trabalhadores do país, ainda mais do meio rural.

No presente artigo pretendemos discutir o modelo de que supostamente levaria ao desenvolvimento traçado pelo governo da Frente Patriótica Ruandesa, liderado por Paul Kagame, principalmente no modo 
que os trabalhadores ruandeses sofrem com um governo autoritário que promove um ajuste estrutural rigoroso, seguindo parte da cartilha neoliberal, principalmente no que tange o acesso à terra, as leis trabalhistas e a estrutura do Estado.

Para tal, discutimos num primeiro momento o caráter do autoritarismo do governo de Ruanda, refletindo como no processo histórico recente de ruandês foi promovida a concentração de poder ao redor de Paul Kagame possibilitando a violência contra a oposição e a população, manipulação de dados e a intervenção em países vizinhos fragilizados, como a República Democrática do Congo. Em seguida demonstramos as principais ações que envolvem as medidas de ajuste estrutural no país, principalmente no que tange a regulamentação da terra e sua relação com o mercado, a visão de eficiência do Estado com paralelos empresariais, e a reforma trabalhista. Por fim, discutimos o modelo de econômico proposto pelo governo da Frente Patriótica Ruandesa no que tange à produção cafeeira e a mineração de metais valiosos.

\section{Reconstrução e autoritarismo na Ruanda pós-genocídio: concentração de poder e perseguição à oposicionistas}

O genocídio de Ruanda tem fim em julho de 1994 quando a Frente Patriótica Ruandesa, liderada por Paul Kagame, toma a capital do país, expulsando e prendendo de Kigali parte dos perpetuadores do genocídio e do antigo regime da Segunda República Ruandesa (1973-1994) liderada pelo General Juvenal Habyarimana. O combate contra os perpetuadores do genocídio fez com que a Frente Patriótica Ruandesa gozasse de prestígio 
para participar da reconstrução de um país destruído por uma guerra civil e crise econômica, no entanto, eram poucos os membros da FPR que conheciam efetivamente Ruanda, na medida em que muitos de seus membros estavam anos exilados em Uganda, ou ainda nasceram no país vizinho devido ao exílio de seus pais, sem nunca terem ido para o território ruandês (TWAGIRAMUNGU, 2015, p. 9).

É importante recordar aqui que a Frente Patriótica Ruandesa nasce como uma oposição armada ao governo de Juvenal Habyarimana composta por exilados, ou filhos de exilados ruandeses, que foram expulsos de seu país no decorrer de décadas a partir de episódios de violência política e/ou étnica desde a Revolução Hutu de $1959 .{ }^{2}$ Desta forma, a FPR ficou marcada como sendo uma organização de tutsis, mas era composta também por hutus opositores ao governo da Primeira República Ruandesa (1962-1973) e da Segunda República Ruandesa (1973-1994). A principal oposição armada de Ruanda foi treinada em Uganda e é a partir de seu país vizinho que iniciam as primeiras incursões militares que no início de 1990 resultam na Guerra Civil Ruandesa e no subsequente genocídio em 1994.

Com o término do genocídio, fica instaurado um governo de transição, unidade e reconciliação a partir da estruturação de um novo parlamento pluriétnico em 1994 e uma Suprema Corte em 1995. O novo governo ruandês, que tinha a frente o Premier hutu Fautin Twagiramungu, enfrentava o poder paralelo da FPR, que possuía maior legitimidade em boa parte do país (com exceção das regiões que sofreram maior perseguição e

${ }^{2}$ A Revolução Hutu de 1959 foi um processo de revolta no decorrer da colonização belga em que ruandeses contrários à monarquia tutsi invadiram as propriedades dos aristocratas ligados ao monarca e expulsaram do país a família real ruandesa e outros milhares de outros ruandeses favoráveis à monarquia (em sua grande maioria tutsis). 
represália após o genocídio), o que corroborou com o colapso do governo em agosto de 1995 (TWAGIRAMUNGU, 2015, p. 9).

A força política e militar da FPR e de Paul Kagame aumentam consideravelmente a partir de 1998, em que o General consegue concentrar o poder partidário em suas mãos, principalmente após a interferência no país vizinho da República Democrática do Congo na chamada Primeira Guerra do Congo (1996 - 1997), o que deu a Kagame a confiança de países ocidentais ao ajudar desestabilizar o governo congolês. ${ }^{3}$ Com essa centralidade partidária, Kagame consegue realizar importantes indicações políticas para cargos importantes da administração do governo ruandês, o que leva a instabilidade e a renúncia do então presidente Pauster Bizimungu em 2000, fazendo com que o então vice-presidente Paul Kagame assumisse a presidência e ficasse com o caminho livre para a eleição presidencial de 2003.

Desde sua eleição, o agora presidente Kagame vem aumentando o seu poder e de seu partido, vencendo eleições com a expressiva marca acima dos 90\% nos anos de 2003 (com 95\% dos votos), 2010 (com 93,08\% dos votos) e 2017 (com 98,8\% dos votos), mas que constantemente são indicada como eleições não livres. No total, Paul Kagame já acumula 20 anos ininterruptos na presidência, e possui mandato até 2024.

\footnotetext{
${ }^{3}$ A Primeira Guerra do Congo teve como um de seus motivos mais imediatos uma fragilidade do regime de Mobutu, fazendo com que a oposição tomasse Kinshasa com apoio da Frente Patriótica Ruandesa, liderada por Paul Kagame, o qual lançou ofensivas contra hutus congoleses em um movimento de contra-genocídio. A primeira guerra do Congo deu as bases para a Segunda Guerra do Congo entre 1998 e 2006, em que Ruanda se fez mais presente no leste do país vizinho. Tal conflito que envolveuem torno de uma dezenas de países africanos (e também conhecido como Guerra Mundial Africana), assassinou algo em torno de 3,8 milhões de pessoas.
} 
A política interna de Ruanda faz com que o país seja bastante restrito e fechado, principalmente no que tange as possibilidades de articulação da oposição ao governo da FPR e também a liberdade de imprensa, em que oposicionistas são constantemente perseguidos e até exilados, o que é acentuado em períodos eleitorais, deixando poucos políticos se candidatarem e se promoverem diante da população. Segundo a Anistia Internacional, em matéria vinculada em sua página na internet:

Nas últimas duas décadas, campanhas de difamação, intimidação, desaparecimentos e assassinatos direcionados caracterizaram o espaço político de Ruanda.

A Frente Patriótica de Ruanda (RPF) consolidou seu controle sobre o sistema político de Ruanda, deixando pouco espaço para oposição política. Vozes em desdém - seja na política, na mídia ou na sociedade civil - foram sistematicamente silenciadas.

A partir de então, usando o argumento da unidade nacional e a luta contra o "divisionismo" e a "ideologia do genocídio", o governo de Ruanda restringiu continuamente o espaço cívico. (Anistia Internacional, 2017) [tradução propria]. ${ }^{4}$

O sustentáculo político da FPR, que lhe dá margem de manobra política e legitimidade frente a parte da população, está muito pautado em um discurso de união nacional dos ruandeses, suprimindo as identidades étnicas ruandesas, em que todos que nascem em Ruanda são apenas ruandeses.

4 No original: Over the past two decades, smear campaigns, intimidation, disappearances and targeted killings have characterized Rwanda's political space.

The Rwanda Patriotic Front (RPF) has consolidated its control over Rwanda's political system, leaving little room for political opposition.Dissenting voices - whether in politics, the media or civil society - have been systematically silenced.

From then on, using the argument of national unity and the fight against "divisionism" and "genocide ideology", the Rwandan government has continuously restricted civic space. (AMNESTY INTERNATIONAL, 2017). 
Políticos oposicionistas que seguem apontamentos contrários deste proposto pelo governo da FPR, por mais que tivessem uma postura crítica, são proibidos de exercer a política livremente no país, pois são acusados de estarem promovendo a rivalidade e o divisionismo entre os ruandeses, trazendo o perigo do genocídio de volta, conforme é destacado por Dominique E. Uwizeyimana (2014) ao analisar a Law of Genocide Ideology com sua limitações e consequências políticas (UWIZEYIMANA, 2014).

Para além de uma legislação que não dá margem de atuação para a oposição, devemos apontar para a perseguição física, em que muitos oposicionistas precisam buscar o exílio para garantir a própria segurança, na medida em que oposicionistas são presos, com casos de desaparecimento. No entanto, nem no exílio desafetos do governo de Kagame ficam seguros, como foi o caso do atentado que vitimou Patrick Karegeya na África do Sul em 2014, ou ainda os três atentados sofridos por Kayumba Nyamwasa também na África do Sul (TWAGIRAMUNGU, 2015, p. 10).

Outro processo com bastante repercussão e que expressa o autoritarismo da Frente Patriótica Ruandesa foi o fechamento de mais de 700 igrejas evangélicas sob a alegação que faltaria condições de higiene nos locais, no entanto, para Phil Clark, especialista na história recente de Ruanda em entrevista ao Deutsche Welle África, “o encerramento dessas igrejas é um ato muito mais político do que o governo diz. Ele está sinalizando às igrejas, e outras organizações sociais de Ruanda, que elas estão sendo vigiadas. Eu interpreto como um claro aviso" (DEUTSCHE WELLE AFRICA, 2018). 
O autoritarismo ruandês, muitas vezes é tolerado ou até ignorado por potências ocidentais e outros órgãos internacionais na medida que seria justificado pelo sucesso de seu modelo econômico que teria promovido um constante crescimento econômico associado com uma redução significativa da pobreza no país. Segundo o levantamento de dados promovido pelo governo ruandês, a pobreza no país teria saído do patamar de 56,7\% no senso de 2005-06 para 39,1\% no senso de 2013-14, sendo que a extrema pobreza passou, no mesmo período de 35,8\% para 16,3\% (ANSOMS, et al, 2017, p. 48). Tais avanços estatísticos são cruciais para que Ruanda receba ajuda financeira e apoio internacional, desta forma, seria necessário, diante da falta de abertura e do autoritarismo ruandês, termos mais cautela diante de tais dados e buscar uma análise mais minuciosa diante daquilo que este números querem representar na sociedade ruandesa.

Podemos problematizar tais informações a partir de um estudo bastante consistente intitulado "Statistics versus livelihoods: questioning Rwanda's pathway out of poverty" (2017), de An Ansoms, Esther Marijnen, Giuseppe Cioffo e Jude Murison. Segundo a análise dos autores, liderados por An Ansoms, é possível perceber que os dados apresentados pelo governo ruandês teriam uma série de irregularidades e inconsistências, de modo que não seriam confiáveis para se entender efetivamente a pobreza em Ruanda.

Essas inconsistências em levantamento de dados ocorreriam pois, segundo os autores, alguns governos: "tendem a simplificar a vida social com o propósito de reduzi-la a indicadores estatísticos que podem ser usados para dar força a ideias específicas de 'modernidade' e ‘desevolvimento', com propósito de suportar ideias políticas e, no caso de 
Ruanda, facilitar o acesso a dinheiro de doações.” (ANSOMS, et al, 2017, p. 49) [tradução própria]. ${ }^{5}$

Além da busca por auxilio de assistência financeira, podemos complementar que o governo ruandês também poderia demonstrar tais dados inconsistentes para adquirir mais legitimidade diante da comunidade internacional, de modo a conquistar um maior apoio político frente as tensões internas e externas que Paul Kagame enfrenta, o que também facilitaria a obtenção de investimentos e financiamento, deixando mascarada a postura autoritária da Frente Patriótica Ruandesa e sua cúpula.

Os autores supracitados questionam os números estatísticos apresentados, com uma comparação entre os dados públicos e uma pesquisa de campo que valoriza as condições de vida da população ruandesa, com o intuito de entender a dinâmica da pobreza em Ruanda no cotidiano dos mais pobres, principalmente dos trabalhadores do campo, o que dá margem para questionar a veracidade e/ou a precisão dos dados. Ansoms e sua equipe entendem que um dos pontos sensíveis das pesquisas seria a alteração do método em que a linha da pobreza foi reduzida (ANSOMS, et al, 2017, p. 48). Além dessa mudança de método, o que seria mais grave para os pesquisadores, é a não contemplação ou omissão de parte da população ruandesa justamente entre as pesquisas que mais demonstrariam a redução da pobreza, resultando em uma subrepresentação de uma parcela de ruandeses, principalmente daqueles mais jovens, já que entre as pesquisas de 2005-06 e 2010-11 seria possível

\footnotetext{
${ }^{5}$ No original: tend to simplify social life in order to reduce it to statistical indicators that may be used for advancing specific ideas of 'modernity' and 'development', in order to support political claims and, in the case of Rwanda, to facilitate access to aid money (ANSOMS, et al, 2017, p. 49).
} 
observar que "sumiram" 294 mil jovens das pesquisas (ANSOMS, et al, 2017 , p. 53). Os jovens ruandeses, assim como de outras territorialidades em nossa contemporaneidade, são um dos que mais sofrem as mazelas do neoliberalismo, com altas taxas de desemprego e pobreza, no caso específico de Ruanda, os jovens ruandeses não conseguem empregos nas cidades e também não conseguem um acesso seguro a terra (ANSOMS, et al, 2017, p. 53).

Os autores também destacam que:

Em uma análise crítica dos dados das pesquisas domiciliares, Carr-Hill percebe que as pesquisas sub-representam seis subgrupos mais vulneráveis: (1) os sem-teto, (2) aqueles em instituições, (3) populações móveis, nômades ou pastores, (4) aqueles em famílias frágeis e desarticuladas, (5) populações de favelas e (6) áreas que apresentam riscos à segurança. De acordo com Carr-Hill (2014, p. 136), "esses seis subgrupos constituem uma grande fração dos" mais pobres entre os pobres ", e sua omissão no "denominador" provavelmente insere vieses substanciais nas avaliações de pobreza. Esse argumento também pode ser relevante ao considerar o contexto de Ruanda. É bem provável que populações desabrigadas, móveis ou ilegítimas que vivem em favelas nas fronteiras de Kigali estejam sub-representadas no conjunto de dados geral (ANSOMS et al. 2017, p. 52) [tradução própria]. ${ }^{6}$

Nessa medida, o combate contra a pobreza promovida pelo governo ruandês envolveria esconder a pobreza ou até mesmo camuflar os mais pobres com medidas contraditórias que envolvem manuais de

${ }^{6}$ No original: In a critical analysis of household survey data, Carr-Hill notices that surveys typically under-represent six vulnerable subgroups: (1) the homeless, (2) those in institutions, (3) mobile, nomadic or pastoralist populations, (4) those in fragile disjointed households, (5) slum populations, and (6) areas posing security risks. According to Carr-Hill $(2014,136)$, 'those six subgroups constitute a large fraction of the "poorest of the poor",' and their omission in the 'denominator' is likely to insert substantial biases in poverty assessments. This argument might also be relevant when considering the Rwandan context. It is quite likely that homeless, mobile populations, or those illegitimately living in slums at the borders of Kigali, are under-represented in the overall dataset (ANSOMS et al. 2017, p. 52). 
condutas rigorosos para os trabalhadores mais pobres. Sob a suposta bandeira de combater a pobreza e modernizar a sociedade ruandesa, o governo da Frente Patriótica Ruandesa impôs condutas e posturas para que a população camufle a sua pobreza, como é o caso da proibição de andar descalço e a obrigatoriedade de se utilizar sapatos, com o que o governo chama de "roupas decentes" e sempre limpas (ANSOMS, 2009, p. 304), já que para o governo ruandês a pobreza de seus trabalhadores seria também devido à uma pobreza de espírito e comportamento. Tal processo trata-se de um processo de criminalização da pobreza e da classe trabalhadora em que “uma 'modernidade imposta' que parece resultar em nada mais do que a atualização cosmética da vida rural, enquanto oculta a verdadeira extensão da pobreza. Na Ruanda contemporânea, parece ter sido 'proibido pela política oficial' ser pobre" (ANSOMS, 2009, p. 305).

Outro ponto que nos chama atenção é o intervencionismo indevido que o governo de Paul Kagame faz nos países vizinhos, principalmente na fronteira oeste com a República Democrática do Congo. Essa intervenção corroborou diretamente com a primeira e a segunda Guerra do Congo, entre 1996 - 1997 e 1998 - 2003, respectivamente, e que deixou quase 4 milhões de mortos, se configurando como um dos mais duros conflitos do século XXI. O exército da Frente Patriótica Ruandesa atuou diretamente no território ruandês, trabalhando para desestabilizar o Estado vizinho em uma atuação que servia tanto por interesses econômicos de Ruanda e potências ocidentais (como os Estados Unidos da América), em que soldados da FPR faziam pilhagem de metais valiosos (conforme veremos mais adiante), além de interesses geopolíticos ligados tanto a Ruanda como às mesmas potências ocidentais. 


\section{Ajuste estrutural: o acesso à terra, modelo de governança e reforma trabalhista}

Essa postura autoritária do governo ruandês está atrelada, e é um importante sustentáculo, da sua política econômica com inspiração neoliberal. O governo da Frente Patriótica Ruandesa assumiu o país em 2000 com um compromisso de realizar um ajuste estrutural bastante rígido, promovendo regulamentação da propriedade privada, reforma da estrutura do estado e reforma das leis trabalhistas. Se dirigindo pela cartilha neoliberal e com amplo apoio do Banco Mundial, o governo ruandês atacou profundamente o modo que a própria população ruandesa entendia o acesso à terra, as funções do Estado e o local do trabalho, promovendo uma série de dificuldades para os trabalhadores ruandeses.

No que tange o acesso à terra, precisamos ter em mente que os conflitos da década de 1994 desarticularam de modo bastante significativo a produção agrária e a organização territorial dos lotes dos trabalhadores rurais ruandeses. Com o assassinato de centenas de milhares de tutsis e hutus moderados, além da fuga de milhões de outros ruandeses para países vizinhos, milhares de lotes de terra ficaram aparentemente abandonados, ou sem dono, e muitos outros foram apropriados a partir da violências da guerra e do genocídio, o que estava, evidentemente, a margem da legislação e dos costumes dos ruandeses.

Com o intuito de regularizar a posse da terra em todo território, o governo do General Paul Kagame realizou uma série de esforços e lançou 
uma legislação para gestar um novo entendimento acerca do que era a propriedade, sua posse e sua função social mais voltada para a produção.

Desta legislação destaca-se a National Land Policy de 2004, que expressa com clareza a seu propósito:

Além de alguns regulamentos fundiários dispersos, a maioria dos quais remonta ao período colonial, Ruanda nunca teve uma política fundiária adequada nem uma lei fundiária, uma situação que aprimora a dualidade existente entre a lei escrita muito restritiva e a lei do Direito consuetudinário amplamente praticado, dando origem à insegurança, instabilidade e precariedade da posse da terra. Portanto, o governo de Ruanda considerou convincente e necessário estabelecer uma política nacional de terras que garantisse uma forma segura e estável de posse da terra e propiciasse um uso racional e planejado da terra, ao mesmo tempo em que assegurava um bom gerenciamento e uma administração eficiente da terra (MINITERE, 2004, p. 5) [tradução própria]. ${ }^{7}$

Após a implementação da National Land Policy, busca-se regularizar as propriedades ruandesas, principalmente a partir do Land Tenure Regularization Program de 2010, em que buscou-se regularizar mais de 10 milhões de propriedades (NIYONSENGA, ILBERG, NKURUNZIZA, 2018). Essa regularização das propriedades muda de maneira significativa o modo com que a terra é entendida e administrada em Ruanda, na medida que a centralidade desse processo estava na garantia da propriedade privada e consolidar uma suposta segurança produtiva ao proprietário, em detrimento de questões coletivas como é o caso da

\footnotetext{
${ }^{7}$ No original: Apart from a few scattered land regulations, most of which date back to the colonial period, Rwanda has never had a proper land policy nor has it ever had a land law, a situation that enhances the existing duality between the very restrictive written law and the widely practised customary law, giving rise to insecurity, instability and precariousness of land tenure. The Rwandan Government, therefore, found it compelling and necessary to establish a national land policy that would guarantee a safe and stable form of land tenure, and bring about a rational and planned use of land while ensuring sound land management and an efficient land administration (MINITERE, 2004, p. 5).
} 
segurança alimentar do país, o acesso costumeiro a terra e também o direito consuetudinário que o sustenta.

Este processo de regularização da terra, segundo Moyo, Tsikata e Diop (2015), é uma tendência que perpassa por outras territorialidades africanas, não sendo exclusivo em Ruanda. Segundo os autores, a partir de 2004 mais de vinte países africanos passaram por processos de regularização do acesso à terra enquanto propriedade privada, deixando-os a mercê do mercado internacional. A regularização da terra no continente africano faz parte de uma série de pressões que vem principalmente de órgãos de financiamento internacionais e em consonância com a visão ortodoxa da economia que possui o Banco Mundial, na medida em que para tal concepção econômica a:

permanência da ausência de direitos de propriedade fundiários negociáveis e claros limites da 'segurança de posse' se constitui uma barreira fundamental ao investimento e desenvolvimento. [...] Argumenta-se que a ausência de direitos de propriedade privada da terra significa que a África está assentada em capital morto (MOYO, TSIKATA, DIOP, 2015, p. 2) [tradução própria]. ${ }^{8}$

O resultado de tal processo tem sido catastrófico para trabalhadores rurais em muitos países, e em Ruanda não é diferente. Conforme "O significado da terra em Ruanda tem mudado de ser um modo básico de vida e contínua subsistência para uma commoditie de mercado em processo de desenvolvimento" (NIYONSENGA, ILBERG, NKURUNZIZA, 2018, p.

\footnotetext{
${ }^{8}$ No original: "remains that the absence of clear tradeable landed property rights limits 'tenure security', and constitutes a fundamental barrier to investiment and development. [...] It has been argued that the absence of private property rights in land means that Africa's is sitting on dead capital" (MOYO, TSIKATA, DIOP, 2015, p. 2).
} 
76), o acesso a terra para os mais jovens ficou dificultado, causando um aumento do desemprego, além de desordenado crescimento das cidades.

Por outro lado, o governo da Frente Patriótica Ruandesa entendeu que a regularização da propriedade seria um elemento fundamental para o aumento da produtividade e do desenvolvimento econômico do país, o que fica claro no Economic Development and Poverty Reduction Strategy II (EDPRS2), documento que segue as recomendações do Banco Mundial, entendendo que a segurança da propriedade privada e seus direitos seriam elementos centrais para que Ruanda se habilitasse em um mundo do livre mercado. Para o EDPRS2 (2013), em seu prefácio assinado pelo próprio presidente da República de Ruanda, Paul Kagame:

O período da EDPRS 2 é o momento em que nosso setor privado deve assumir a liderança no crescimento econômico e na redução da pobreza. Através dessa estratégia, focaremos os esforços do governo na transformação da economia, do setor privado e no alívio de restrições ao crescimento do investimento (EDPRS2, 2013, p. XII) [tradução própria]. ${ }^{9}$

Podemos observar que com esta concepção econômica liberal, o setor privado (nacional ou não) é habilitado a participar e dirigir o desenvolvimento econômico do país, em que caberia ao mercado combater e regular a pobreza, a segurança alimentar, o empoderamento feminino e a boa governança (EDPRS2, 2013), deixando o Estado fora de pontos tão sensíveis da sociedade contemporânea. No entanto, os impactos sociais e as consequências de tais medidas em Ruanda são bastante sensíveis.

\footnotetext{
${ }^{9}$ No original: The EDPRS 2 period is the time when our private sector is expected to take the driving seat in economic growth and poverty reduction. Through this strategy we will focus government efforts on transforming the economy, the private sector and alleviating constraints to growth of investment (EDPRS2, 2013, p. XII).
} 
Outro ponto fundamental dentro da proposta de governo da Frente Patriótica Ruandesa, que está atrelado a gestão de um Estado neoliberal, é a visão da necessidade de se gestar um Estado com caráter empresarial. É possível refletir sobre essa visão empresarial na política ruandesa a partir da obra "Rwanda, inc", de Patricia Crisafulli e Andrea Redmond (2012), que foi financiada pela VISA Inc - com direito à um prefácio elogioso por parte do diretor comercial da companhia - o seu caráter quase que panfletário busca enaltecer a política ruandesa e os seus supostos avanços econômicos e sociais. Diante de tal postura, as autoras classificam o presidente Paul Kagame e sua forma de liderança como:

O estudo de sua liderança em Ruanda revela um forte paralelo com um líder corporativo; sua visão compreensiva, exigindo atenção aos detalhes, e direcionando a execução. De fato, a maneira que ele lidera Ruanda - como um pro-setor privado, economia de livre mercado com governança estruturada que favorece a transparência e a defesa de tolerância zero com a corrupção (CRISAFULLI, P. \& REDMOND, A. 2012, p. 16) [tradução própria]. ${ }^{10}$

No corpo da obra, Crisafulli e Redmond colocam o presidente Paul Kagame como um elemento central para os supostos avanços de Ruanda, principalmente devido a essa postura empresarial, em que o presidente ruandês possuiria uma gestão e política "mais moderna”, fugindo do que as autoras classificam como "modo africano tradicional" de se entender a política e o Estado, o que seria entendido como algo danoso aos países africanos.

\footnotetext{
${ }^{10}$ No original: A study of his leadership in Rwanda reveals strong parallels to a corporate leader; his comprehensive vision, exacting attention to details, and drive for execution. Indeed, the way he leads Rwanda - as a pro-private sector, free market economy with governance structures that enhance transparency and uphold zero tolerance for corruption (CRISAFULLI, P. \& REDMOND, A. 2012, p.16).
} 
Essa postura empresarial, quase de um executivo, valorizada pela visão neoliberal no contexto contemporâneo, é expressa nas medidas que o governo toma na valorização da governança e eficiência dos servidores públicos, os quais são submetidos a metas rigorosas. A postura de gestar metas é uma importante bandeira do governo ruandês e está atrelado às políticas de Home Grow Solutions, que são políticas públicas baseadas em soluções caseiras que estariam ligadas aos costumes e tradições locais da sociedade Banyarwanda ${ }^{11}$, às quais são readaptadas dentro de um contexto contemporâneo (RWABYOMA, 2016, p. 318). Deste modo, o governo ruandês não seria um mergulho cego à uma modernidade ocidental, na medida que busca também na tradição local a legitimidade para gestar as suas reformas, apesar de na maioria das vezes tais tradicionais serem tratadas de modo anacrônico e a serviço da gestão de um estado neoliberal. Assim como em muitos países de nossa contemporaneidade em que o neoliberalismo se faz hegemônico, em Ruanda existe um movimento de conservar costumes e liberalizar a economia.

Dentre as principais Home Grow Solutions adotadas pelo governo ruandês, aquela que regula o sistema de metas públicas e a eficiência é o Imihigo. Esta suposta solução caseira baseada na tradição Banyarwanda se configura como uma forma de contrato por performance, em que se exige

\footnotetext{
${ }^{11}$ Os Banyarwandas foram um único povo que habitou a região que hoje é Ruanda. Apesar de ser um povo dividido por castas baseadas em ofícios, como os tutsis e hutus, era um povo que possuía uma única língua (o kinyarwanda) e uma estrutura política e cultural unificada e sólida. Com a dominação colonial, os Banyarwandas mudaram significativamente as suas formas de organização, com o entendimento de que as castas locais representariam diferenças raças que deveriam ser hierarquizadas. $\mathrm{O}$ governo de Paul Kagame visaria resgatar os valores da sociedade Banyarwanda, o que muitas vezes ocorre de forma distorcida para fortalecer o projeto de seu partido.
} 
metas para alguns de setores da sociedade ruandesa, promovendo a competitividade em servidores. Segundo Bert Ingelaere, os contratos do Imihigo "referem-se à capacidade de mostrar aos observadores e à outros que um possui a capacidade e a competente na execução de uma tarefa." (INGELAERE, 2009, p. 454) [tradução própria]. ${ }^{12}$

Também precisamos destacar as medidas do governo da Frente Patriótica Ruandesa que realizaram uma profunda reforma trabalhista no pais. A legislação trabalhista foi reformada e dois momentos, primeiro em 2009 com a Lei 13/2009, e depois com a Lei 66/2018 Regulationg Labour in Rwanda (WAWERU, 2019, p. 8). A nova legislação trabalhista ruandesa, apesar de possuir alguns avanços no que tange a discriminação de origem e gênero, possui uma grande inspiração neoliberal, possibilitando uma flexibilização do trabalho a partir da suposta livre negociação entre patrões e trabalhadores, em que a negociação se dá individualmente e não como categoria, o enfraquece as entidades trabalhistas, e, consequentemente, deixando os trabalhadores mais sujeitos às necessidades dos empregadores. A flexibilização dos contratos trabalhistas é tamanha em Ruanda, que é possível realizar contratos verbais de trabalho no decorrer do prazo de 90 dias, sem segurança para os trabalhadores. Alem disso, a instabilidade também ocorre no caso dos contratos assinados entre patrões e trabalhadores, na medida em que os patrões possuem o direito de alterar contratos e suspender pagamentos em uma diversidade de casos, como em greves (legais ou não), dificuldade financeira, entre outros que, inclusive, ficam em aberto na legislação (WAWERU, 2019, p. 9).

\footnotetext{
${ }^{12}$ No original: refer to the capability to show observers and others that one is capable and competent in the execution of a task (INGELAERE, 2009, p. 454).
} 


\section{O modelo econômico da Frente Patriótica Ruandesa: metas de produção agrícola e a pilhagem de minérios valiosos}

O ajuste estrutural promovido pelo governo ruandês, com a mudança no entendimento e da legislação no que tange o acesso e o trabalho na terra, além de novos sentidos para o mundo do trabalho e do Estado está atrelado ao modelo de desenvolvimento econômico proposto pela Frente Patriótica Ruandesa, que tem como seus dois pilares a exportação de café e minerais valiosos, em que hoje correspondem cada um a quase $40 \%$ da exportação do país.

A produção e exportação cafeeira foi entre as décadas de 1930 e 2000 o principal produto a compor o PIB ruandês, passando pelo período colonial dominado pelos belgas (1918-1962), a Primeira República Ruandesa (1962-1973) e a Segunda República Ruandesa (1973-1994), sendo que neste último período a produção cafeeira chegou a corresponder a $90 \%$ do Produto Interno Bruto. Esta produção de café, no período independente pré-genocídio, era baseada em milhares de pequenos lotes, em que os trabalhadores rurais tinham o usufruto da terra, sem o entendimento de uma propriedade privada, assim como em muitos países africanos. Neste usufruto da terra, os trabalhadores poderiam produzir a sua subsistência e também eram obrigados a produzir café e vende-lo para o Estado.

Para o governo da Frente Patriótica Ruandesa, esse modelo de produção e de acesso à terra era entendido como ineficiente e deveria combater o acesso costumeiro a terra, desta forma ocorre um direcionamento político para reestruturação do desenvolvimento e da 
produção agrária em que, segundo Ansoms (2009, p. 296), envolveria três eixos principais: (1) modernização forçada e artificial do meio rural ruandês; (2) transformação do setor agrícola ruandês em um motor profissionalizado do crescimento econômico, centrado principalmente na competitividade e nas unidades de fazenda comerciais; (3) produção agrícola realizada a partir de metas rigorosas.

Com o intuito de combater o que a Frente Patriótica Ruandesa entendia como um atraso no meio rural ruandês, o governo buscou promover uma produção agrícola mais mecanizada, entendido como um processo de modernização para o desenvolvimento do país, no entanto essa modernização ocorre de modo forçado, em que os trabalhadores rurais ruandeses ficam obrigados a produzir aos moldes exigidos pelo governo com "imposição de grãos com preferência de orientação de mercado por região" (ANSOMS, et al, 2017, p. 56) [tradução própria], ${ }^{13}$ em que o pequeno produtor precisa atingir metas produtivas, de modo a perder a sua própria autonomia, fazendo com que este muitas vezes não consiga acompanhar o ritmo exigido pelo governo em que "pequenos fazendeiras reportaram baixa segurança alimentar como o resultado da perda de seu controle diante de seu processo produtivo" (ANSOMS, et al, 2017, p. 56).

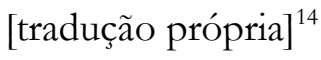

Para este processo de modernização forçada do campo, além de o governo buscar uma maior eficiência e produtividade agrícola com a mecanização e metas, o diagnóstico produzido pela Frente Patriótica

13 No original: "imposition of preferential market-oriented crops per regins" (ANSOMS, et al, 2017, p. 56).

${ }^{14}$ No original: smallholder farmers reported lower food security as a result of a loss of ownership over their productive processes (ANSOMS, et al, 2017, p. 56). 
Ruandesa é de que seria necessário aumentar o tamanho das propriedades agrícolas, com o entendimento de que Ruanda seria um país que possui muita gente com pouca terra, o que faria com que os trabalhadores rurais se focassem na sua própria subsistência. Este diagnóstico se faz bastante presente no Land National Policy (2004) e é utilizado para justificar os seus fins de reforma, em que seria necessário aumentar as propriedades ruandesa e ofertar empregos não agrícolas para a população desalojada do campo. Essa percepção é reforçada nas palavras de um oficial do Ministry of Agriculture and Animal Resources de Ruanda:

Eles dizem que a agricultura é o setor produtivo, mas não é em Ruanda. . . . De fato, devemos parar de chamá-lo de setor produtivo; é neste momento o setor de subsistência. Neste ponto, a maioria das pessoas não está ganhando porque os terrenos aos quais têm acesso são muito pequenos... Temos que tirar mais pessoas da terra, pois não podemos continuar um sistema com pequenos pedaços de terra... Quando as pessoas saem da terra, haverá mais terra nas mãos de menos pessoas, o que permitirá um melhor planejamento do sistema (ANSOMS, 2009, p. 300) [tradução própria]. ${ }^{15}$

A partir desse discurso de necessidade de aumento produtivo, com aumento de propriedades dos lotes rurais ruandeses com uma reorganização do acesso à terra, o governo de Paul Kagame lançou em 2000 um programa de vilas agrícolas chamado Imidugudu, que possui algumas exigências caras na sua implementação que acaba por expulsar os trabalhadores rurais que não conseguem cumprir as normas e condições

15 They say that agriculture is the productive sector, but it isn't in Rwanda... In fact, we should stop calling it the productive sector; it is at this point the survival sector. At this point, most people are not earning because the pieces of land they have access to are too small... We have to get more people off the land, as we cannot continue a system with small pieces of land... When people get off the land, there will be more land in the hands of fewer people, which will allow a better planning of the system (ANSOMS, 2009, p. 300). 
mínimas para participar do plano. Segundo Hillhorst e Van Leeuwen (2000), as vilas agrícolas do programa Imidugudu:

era uma política de projeto para todo o país, desconsiderando a diversidade local, implementada de cima para baixo e com pouco espaço para participação popular. No caso de Ruanda, parece que o contrário foi alcançado: o desenvolvimento não foi integrado ao alívio, mas as armadilhas do alívio invadiram o desenvolvimento (HILLHORST, D. VAN LEEUWEN, M. 2000, p. 265) [tradução própria]. ${ }^{16}$

Com o intuito de forçar mudanças culturais, técnicas e produtivas, o governo da FPR gestou um controle produtivo bastante rigoroso, que, conforme vimos, retira a autonomia dos trabalhadores, com o intuito de lhes impor uma maior concorrência entre si. A partir disso, o governo busca inserir os trabalhadores rurais ruandeses e suas pequenas propriedades em redes globais de valor, em que tais trabalhadores ficam sujeitos às transnacionais que distribuem sementes, fertilizantes, entre outros produtos, determinando os valores envolvidos tanto na aquisição da matéria prima, como também na venda dos produtos, o que torna trabalhadores rurais de Ruanda, e também de todo o mundo, reféns de dívidas e de um trabalho exaustivo com altas metas.

Quem mais sofre diante de tudo isso são os trabalhadores com menores propriedades e mais pobres, que não conseguem assumir os compromissos da modernização forçada do campo, precisando atingir difíceis metas produtivas para serem melhor remunerados e pagar suas dívidas com insumos, e que muitas vezes precisam vender suas terras para

\footnotetext{
${ }^{16}$ No original: was a blueprint policy for the whole country, disregarding local diversity, implemented in a top-down fashion and with little space for popular participation. In the Rwandan case it seems that the opposite was achieved of what was intended: development was not integrated into relief, but the pitfalls of relief invaded development (HILLHORST, D. VAN LEEUWEN, M. 2000, p 265).
} 
concorrentes que já possuem uma maior acúmulo de terras (ANSOMS, 2009, p. 305).

No entanto, no decorrer do governo de Paul Kagame, aos poucos a produção agrícola e exportação de café deixou de ser o principal produto de exportação do país para dar lugar a exportação de minérios valiosos como ouro, tântalo e tungstênio ${ }^{17}$, sendo que no ano de 2017 Ruanda se tornou o maior produtor de tântalo do mundo. A estabilidade política de Ruanda se tornou um grande atrativo para mineradoras internacionais, que viram no pequeno país uma rota mais estável para a exportação de minérios.

No entanto, existem muitas controversas nessa mineração, na medida em que parte deste produto são adquiridos de maneira ilegal na região fronteiriça com o Congo, o que é possibilitado por conflitos no país vizinho e gestando os chamados minerais de conflitos (KINNIBURGH, 2014).

Não é claro como boa parte de tais minérios são produzidos e por quem são exportados, já que sua controversa origem, faz com que empresas de fachada se estabeleçam em Ruanda para conseguiram pilhar esta matéria prima, em que as condições de trabalho dos mineradores são bastante precárias, muitos dos quais são os jovens que citamos anteriormente que não conseguem mais terras para realizar uma produção agrícola e também não encontram emprego nas cidades ruandesas, restando-lhes a mineração e/ou pilhagem dos minérios valiosos em regiões de conflito ou com pouca regulamentação trabalhista.

${ }^{17} \mathrm{O}$ tântalo e o tungstênio são minerais importantes para a produção de tecnologia de ponta que envolve a aviões, foguetes, smartphones entre outros. Muitas das maiores reservas destes minérios estão localizadas em regiões de conflito. 


\section{Considerações finais}

O governo e a administração da Frente Patriótica Ruandesa, liderado pelo General Paul Kagame, nos parece apresentar de um modo extremado uma tendência no mundo contemporâneo que envolve uma afinidade entre um autoritarismo conservador na política e um liberalismo econômico radical.

A partir de um discurso e uma legislação que permite a interpretação de que oposicionistas podem ser coibidos de exercer a política para evitar um suposto divisionismo que poderia desembocar em um novo genocídio, Paul Kagame consegue evocar um trauma coletivo do passado para impor um projeto de poder que deixa os trabalhadores ruandeses bastante fragilizados.

A fragilidade enfrentada pelos ruandeses, principalmente os trabalhadores, é acentuada não só pelo autoritarismo da Frente Patriótica Ruandesa, mas também pela política econômica neoliberal e sua visão distorcida de desenvolvimento que é implementada a partir dessa postura autoritária, que resulta em desemprego, falta de segurança alimentar e acesso à terra, subemprego na mineração de metais valiosos e falta de segurança trabalhista.

Ao lançar um projeto de regulamentação da terra, com o aumento do tamanho das propriedade e metas produtivas altas, pequenos produtores, trabalhadores rurais e, principalmente os mais jovens, acabam por não encontrar alternativa a não ser no trabalho de mineração que, conforme vimos, possuem um processo de violência e pilhagem 
envolvidos. Somado a este processo, as reformas trabalhistas promovidas pela Frente Patríotica Ruandesa também possibilitam um modelo de desenvolvimento perverso, que deixa os trabalhadores bastante expostos às necessidades de seus patrões, além de amarras para o próprio subdesenvolvimento.

Frente a tudo isso, os caminhos seguidos por Ruanda se tornaram um modelo aos olhos do Banco Mundial que deveria ser seguido pelos outros países africanos, ficando evidente o quanto a proposta de desenvolvimento de tais órgãos internacionais não condizem e não se preocupam com a democracia e a qualidadede vida das classes trabalhadoras.

\section{Referências Bibliográficas}

AMNESTY INTERNATIONAL, Rwanda's repressive tactics silence dissent before elections, 2017, in:

https://www.amnesty.org/en/latest/campaigns/2017/08/rwandasrepressive-tactics-silence-dissent-before-elections/

ANSOMS, A. Re-engineering rural society: the visions and ambitions of the Rwandan elite. African Affairs, 108/431, Oxford, Oxford university press, pp. 289-309, 2009.

ANSOMS, A.; MARIJNEN E.; CIOFFO, J.; MURISON, J. Statistics versus livelihoods: questioning Rwanda's pathway out of poverty. Review of African Political Economy, v. 44, no 151, pp. 47-65, 2017.

ANSOMS, A. (2011). Rwanda's Post-Genocide Economic Reconstruction. The Mismatch between Elite Ambitions and Rural Realities. In S. STRAUS, S., WALDORF, L. (eds), Remaking Rwanda. State Building and Human Rights after Mass Violence. Madison: The University of Wisconsin Press, 240-51. 
BADI, M. La globalización neoliberal: las alternativas africanas. Buenos Aires, Revista Theomai, n. 17, 2008.

BLAIR, T., BUFFET, H. Stand with Rwandans. Now is no time to cut aid to Kigali. Foreign Policy, February 21. 2013

CLARK, P. The Gacaca Courts, Post-Genocide Justice and Reconciliation in Rwanda. Justice without Lawyers. London: Cambridge University Press, 2010.

CRISAFULLI, P.; REDMOND, A. Rwanda, Inc.: how a devastated nation became an economic model for the developing world. Nova Iorque, Palgrave Macmillan, 2012.

FONSECA, D. F. da. A mídia ruandesa no genocídio de 1994: a relação entre tutsis, Inkotanyis e a Frente Patriótica Ruandesa. Em Tempo de Histórias, v. 22, p. 56-77, 2013.

FONSECA, D. F. da. África entre classes e etnias: África do Sul (19481994) e Ruanda (1959-1994). Saarbrücken: Novas Edições Acadêmicas, 2015.

HILLHORST, D.; VAN LEEUWEN, M. Emergency and Development: the Case of imidugudu, Villagization in Rwanda, Journal of Refugee Studies v. 13, n. 3, 2000.

INGELAERE, B. Living the transition: Inside Rwanda's conflict cycle at the grassroots. Journal of Eastern African Studies, v. 3, n. 3, p. 438-463, 2009.

GOUREVITCH, P. The Life After. Fifteen years after the genocide in Rwanda, the reconciliation defies expectations. The New Yorker, maio 4: 35-50, 2009.

KIMONYO, J. P.; NOEL, T.; KAYUMBA, C. Supporting the Postgenocide Transition in Rwanda. The Role of the International Community. The Hague: Clingendael-CRU, 2004.

KINNIBURGH, C. Beyond "Conflict Minerals": The Congo's Resource Curse Lives On. Dissent, v. 61, n. 2, pp. 61-68, 2014. 
KINZER, S. A Thousand Hills. Rwanda's Rebirth and the Man Who Dreamt about It. Hoboken, NJ: John Wiley \& Sons Inc. 2008.

MAMDANI, M. When victms become killers: colonislism, nativism and the genocide in Rwanda, Princeton: Princeton University Press, 2002.

MINITERE, National Land Policy. Kigali, 2004.

MOYO, S.; TSIKATA, D.; DIOP, Y. Introduction: Africa's diverse and changing Land Questions. In: (orgs.), Land in the struggles for citizenship in Africa. Dakar: Codesria, 2015.

NIYONSENGA, D. ILBERG, A. NKURUNZIZA, D. The Impact of Land Reform on Land Market Activity in Rwanda and Suggestions in Support of Sustainable Urban Development, Journal of Civil Engineering and Architecture, n. 12, pp. 75-81, 2018.

RWABYOMA, A. Terrains of glocalisations struggles: home-grown initiatives and endogenous development in Rwanda. Humanities and social sciences, 2016.

STRAUS, S. The order of the genocide: race, power, and war in Rwanda. Ithaca, Cornell University Press, 2006.

STRAUS, S., WALDORF, L. (eds) Remaking Rwanda. State Building and Human Rights after Mass Violence. Madison: The University of Wisconsin Press, 2011.

SUNDBERG, M. Training for Model Citizenship: An Ethnography of Civic Education and State-Making in Rwanda, Upsalla, Palgrave Macmillan US, 2016.

REYNTJENS, F. Rwanda, Ten Years On: From Genocide to Dictatorship. African Affairs, 103, 177-210, 2004.

TWAGIRAMUNGU, N. Embracing Neo-liberalism in Uganda and Rwanda, in: LAHAI, J., LYONS, T. (org,) African Frontiers: Insurgency, Governance and Peacebuilding in post-Colonial States. New York: Routledge, 2015. 
UWIZEYUMANA, D. Aspects and Consequences of the Rwandan Law of Genocide Ideology: A Comparative Analysis, Mediterranean Journal of Social Sciences, MCSER Publishing, Rome-Italy, v. 5 n. 23, November, 2014.

WAWERU, F. An overview of New Labour in Rwanda. Research on Humanities ans Social Sciences, v. 9, n. 18, 2019.

WORLD BANK, World Bank Development Indicators, 2015. In: databank.worldbank.org 